\title{
Socio demographic profile and utilization pattern of antipsychotic drugs among schizophrenic inpatients: a cross sectional study from western region of Nepal
}

Indrajit Banerjee ${ }^{1 *}$, Bedanta Roy ${ }^{2}$, Brijesh Sathian ${ }^{3}$, Indraneel Banerjee ${ }^{4}$, Prasanta Kumar Chakraborty ${ }^{5}$ and Archana Saha ${ }^{6}$

\begin{abstract}
Background: Currently a large number of atypical antipsychotics available in the market are endorsed as better option for treating schizophrenia than the typical antipsychotics. Information regarding the utilization pattern of antipsychotic drugs is lacking in Nepalese population particularly in Western Nepal. By means of this study one is expected to acquire an idea concerning clinician's preference to the antipsychotic drugs in actual clinical setup. The main objective of the study was to find the commonest antipsychotics prescribed in a tertiary care center among hospitalized patients in Western Nepal.

Methods: This cross sectional study was carried out between 1st January 2009 and 31th December 2010 at Manipal Teaching Hospital, Nepal. The diagnosis of schizophrenia was based on ICD-10 (Tenth revision).The main outcome variables of the study was commonest antipsychotic drug prescribed. Z test, Chi square test and logistic regression were used for analytical purpose. P-value $<0.05$ was considered to be statistically significant. This is the first study done on the utilization pattern of antipsychotics drugs among hospitalized patients in Nepal.

Results: Out of 210 cases of schizophrenia, most of the patients were less than $40 \mathrm{yrs}$. $78.6 \%$, male $61.9 \%$, unemployed $86.7 \%$ and having their monthly income less than NPR $10000 /$ month $80.5 \%$. As far as religion, $78.1 \%$ patients were the Hindus and ethnically schizophrenia was common among the Dalit $26.2 \%$. The study revealed that $46.2 \%$ of patients were students followed by $25.2 \%$ of housewives. Olanzapine was the commonest antipsychotic drug to be prescribed $34.3 \%$. It was observed that the psychiatrists had a tendency of using antipsychotic drugs by trade names [OR $3.3(1.407,8.031)]$ in male patients as compared to female patients.

Conclusion: According to the utilization pattern of antipsychotics, it is concluded that atypical antipsychotics were used relatively more commonly than that of typical antipsychotics. Among the atypical antipsychotic drugs, there is a trend of using Olanzapine during Schizophrenia as compared to other atypical antipsychotic drugs in Western Nepal.
\end{abstract}

Keywords: Antipsychotics, Drug utilization study, Nepal, Psychiatry, Schizophrenia

\footnotetext{
* Correspondence: indrajit18@gmail.com

'Department of Pharmacology, Manipal College of Medical Sciences,

Pokhara, Nepal

Full list of author information is available at the end of the article
} 


\section{Background}

According to WHO, Drug utilization study is defined as a study of marketing, distribution, prescription and uses of drugs in a society highlighting on the resulting medical, social and economic consequences [1]. Medical aspects focus on the need to balance between the risk and the benefits. The benefits are assessed on the basis of drug efficacy in preventing, relieving and curing diseases or their symptoms and complications. Potential risks include short term and long term adverse effects involving special risk factors mainly associated with genetics, disease, environment, nutrition, age, sex, pregnancy, lactation. A social aspect primarily deals with impact of drugs in the society. It focuses on the attitudes of people towards drug use, and current trends of treatment verses insistent use of conventional medicines. The practice of drug abuse and subsequent causes are also essential social components. Economic aspect reflects on the prices and the applicable heath benefits of a given drug. This includes the drug prices, import verses local products and the costs of drug treatment verses non drug treatment. Current and future allocation of national resources to the drug and health budget is also an economic component [2]. Drug utilization research affords a baseline reference point about the effect of diverse interventions on prescribing the concerned drugs.

Globally the prevalence of schizophrenia shows a wide range of differences [3]. It is estimated that the median prevalence of schizophrenia is $4.6 / 1,000$ for point prevalence, 3.3/1,000 for period prevalence, 4.0/1000 for lifetime prevalence and 7.2 for lifetime risk of morbidity across the world [4]. A study conducted by Robin RW et al. reports that globally the lifetime prevalence of schizophrenia is 1\% [5]. According to standardized mortality ratio, the individuals with a complaint of schizophrenia have a 2-3-fold increased mortality risk as compared with the general population $[6,7]$.

Evidently, there is a dearth need of relevant literatures concerning schizophrenia in Nepal as there is no adequate research about it. A recent study conducted at psychiatric clinic in Janakpur, Nepal showed high prevalence of schizophrenia (30\%) [8]. Similar nature of result was found in a tertiary care mental hospital in Kathmandu, Nepal. The research finding stated schizophrenia $(50.1 \%)$ as a common psychiatric disorder [9] whereas a study from Jiri, Eastern Nepal revealed low prevalence of schizophrenia (1.4\%). Comparatively, this figure is quite small as compared to other psychiatric disorders [10]. Studies have shown that the outcome of schizophrenia is better in developing countries [11]. Following the recent evidences of a systemic review and Meta-analysis on antipsychotics among adults with schizophrenia, it has shown that the benefits of atypical antipsychotics over typical antipsychotics remain indecisive because of discrepancy in assessing the result [12]. A study carried out in Nepal indicates that both atypical and typical antipsychotics were effective to reduce the psychopathological symptoms of schizophrenia among Nepalese population. Interestingly, the finding of this study is contradictory to another study which revealed that atypical antipsychotics like Risperidone has quicker and better safety profile than typical antipsychotics like Haloperidol [13]. Nepalese population includes a wide variety of ethnic groups, to name a few, the Brahmin, Chettri, Gurung, Newar, Puns, Magar [14]. The level of knowledge and information with regard to the utilization pattern of antipsychotic drugs among Nepalese population is far less than present requirement. A 2001 study conducted by Shankar PR et al. at outpatient department of Psychiatry in Western Nepal confirms that the utilization pattern of antipsychotics was very low $8.6 \%$ as compared to other psychotropic drugs like antidepressants $45.94 \%$, anxiolytics $19.41 \%$ [15].

The main objective of the study was to find out the commonest antipsychotics prescribed for patient with schizophrenia among hospitalized patients in western Nepal. The specific objectives were to find out whether the antipsychotics were prescribed by generic or trade names, essential or nonessential drugs, drug therapy or combination of drugs and psychotherapy, groups of antipsychotics prescribed, socio demographic details of schizophrenic patients in Nepalese context. This is the first study undertaken in the utilization pattern of antipsychotics among the hospitalized patients in Nepal.

\section{Methods}

\section{Study design and the participants}

The present study was a cross sectional study done at Manipal teaching hospital, Pokhara, Nepal. It is a tertiary care hospital of Western Nepal and has been providing services to patients from 1998 onwards. It was expected that all the critically ill psychiatric cases with schizophrenia will report at this hospital Western Nepal.

\section{Data collection}

The study was carried out between $1^{\text {st }}$ October 2009 and $30^{\text {th }}$ September 2010 at Psychiatric ward in Manipal Teaching hospital. The collected data include socio demographic details such as age $(<40$ years and $>40$ years), gender (male and female), occupation (housewife, teacher, laborer, student, farmer, retired and others), religion (Hindu, Buddhist, Muslim), ethnicity (Brahmin, Chettri, Newar, Dalit and others), employment (employed and unemployed), monthly income NPR $(<10000 /$ month and $>10000 /$ month, groups of drugs (miscellaneous comprising of both typical and atypical antipsychotics combined together, atypical antipsychotics, typical antipsychotics) Treatment (ECT, drug therapy, drug and psychotherapy combined, based on essential drug list (essential or non-essential), trade/generic, commonest antipsychotic drug. Anatomical Therapeutic 
Chemical Code was also used for different antipsychotics prescribed [16].

\section{Inclusion criteria}

The study conducted between 1 st October $2009-30^{\text {th }}$ September 2010, includes 210 cases of critical ones with all types of schizophrenia but there was no age limit of the patients. The diagnosis of the disease was based on ICD-10 (Tenth revision) Classification of mental and behavioral disorders, Diagnostic Criteria for Research [17,18]. The total number of cases includes inpatient psychiatric cases and those were both inpatient and outpatient.

\section{Exclusion criteria}

Out of 565 psychiatry inpatients, 355 patients were excluded following the diagnosis of psychiatric disorder as the study requires the participation of patients who are suffering from Schizophrenia only. Other additional cases, namely depression, anxiety, mania, bipolar disorder, substance abuse, suicidal tendencies and mental retardation were excluded from the study. The out patients were also excluded as the research aims to study about the drug utilization pattern among the patients who were critically ill with schizophrenia.

\section{Sample size calculation}

For $95 \%$ confidence interval and, significance level $\alpha=5 \%$, $\mathrm{P}=90 \%, \mathrm{Q}=10 \%$, allowable error $=5 \%$, required sample size was 171 . $\mathrm{P}=$ percentage of antipsychotic drugs used for the treatment of Schizophrenia. In the pilot study done prior to the original study with 10 patients was admitted in the psychiatry ward with Schizophrenia [18].

\section{Outcome variable}

The main outcome variable was the commonest antipsychotic drug prescribed.

\section{Explanatory variables}

The demographic and psychiatric disorders have been defined at individual level. Factors which are taken into account at individual level were Age $(<40$ years and $>40$ years), gender (male and female), monthly income ( $<10000 /$ month and $>10000 /$ month), employment of the patient (employed and unemployed), occupation (housewife, laborer, student, farmer, retired and others), religion (Hindu, Buddhist, Muslim), ethnicity (Brahmin, Chettri, Newar, Dalit and others).

\section{Ethical committee approval}

Prior the study, ethical committee approval was taken from the institutional ethical committee, Manipal Teaching hospital, Pokhara, Nepal. The Research was conducted in accordance to latest version of the Declaration of Helsinki.

\section{Data management and statistical analysis}

The data collected was analyzed using Excel 2003, R 2.8.0 Statistical Package for the Social Sciences (SPSS) for Windows Version 16.0 (SPSS Inc; Chicago, IL, USA) and EPI Info 3.5.1 Windows Version. The $\mathrm{Z}$ test and chi square test was used to observe the difference between different variables and strength of the relationship with logistic regression. $\mathrm{p}<0.05$ was considered as statistically significant. We calculated odds ratios (OR) and their 95\% confidence intervals $(95 \% \mathrm{CI}) . \mathrm{p}<0.05$ was considered as statistically significant [19].

\section{Results}

\section{Socio demographic background of schizophrenia}

Among 210 schizophrenia patients, 78.6\% were of younger age and less than 40 yrs, $61.9 \%$ male, $86.7 \%$ unemployed and $80.5 \%$ of them having monthly income less than $10000 \mathrm{NPR} /$ month. As far religious background is concerned, most of the patients were Hindus 78.1\% followed by Buddhist 15.2\%, Christian 3.8\% and Muslims $2.9 \%$. However, the majority of patients of schizophrenia were from Dalit communities $26.2 \%$ followed by the Chettri $23.8 \%$. It was also found that $46.2 \%$ of the patients were students, housewife $25.2 \%$ and others $8.6 \%$, retired $6.7 \%$, job holders $5.7 \%$ respectively (Table 1 ).

\section{Schizophrenia and antipsychotic drugs}

Data indicated that most of the schizophrenic patients had been receiving antipsychotics by trade names. Nearly $65.4 \%$ of schizophrenic male patient had received drugs by trade names which was found to be statistically significant $p<0.01$. Though Nepal has essential list of drugs, most of the patients of schizophrenia had received drugs which are not listed there. An association was noticed between the ethnicity and the practice of using drugs from the National drug list of Nepal ( $p=0.0001)$, it was revealed that drugs which were not included in the national drug list of Nepal were also commonly used in the Dalit 26\%, Chettri 24.7\%, Brahmin 12\%, Gurung 12.7\%, Newari 9.3\%, Magar and Pun $4 \%$, others $11.3 \%$ (Table 2).

Table 3 shows cross tabulation information namely socio demographic factors, groups of antipsychotic drugs and the type of treatment given to the schizophrenic patients. Most of the patients received atypical antipsychotics among antipsychotics. There was an association among ethnicity, occupation and religion of the patients with the groups of antipsychotics prescribed. Data shows that $65.5 \%$ patients were Hindus followed by Buddhist 20.2, Christian 6.5\% and Muslims 4.8\% received atypical antipsychotic drugs. Ethnically, atypical antipsychotics drugs were consumed by $22.6 \%$ of Dalit patients, $26.6 \%$ Chettri patients, 9.7\% Brahmin patients, 15.3\% Gurung patients, Magar and Pun $4.8 \%$ and Newar 9.7\%. Likewise, $48.4 \%$ of patients were students followed by housewife. 
Table 1 Cross tabulation between socio demographic factors and schizophrenia in psychiatry inpatients

\begin{tabular}{|c|c|c|c|c|}
\hline \multicolumn{3}{|c|}{ Socio demographic factors } & \multirow{2}{*}{$\frac{\text { P Value }}{0.0001 \dagger}$} & \multirow{2}{*}{$\frac{95 \% \mathrm{Cl}}{[16.1,27.6]}$} \\
\hline & $>40 \mathrm{yrs}$ & $45(21.4)$ & & \\
\hline \multirow[t]{2}{*}{ Age } & $<40$ yrs & $165(78.6)$ & & {$[72.4,83.9]$} \\
\hline & Female & $80(38.1)$ & $0.0001+$ & {$[31.5,45.0]$} \\
\hline \multirow[t]{2}{*}{ Gender } & Male & 130(61.9) & & {$[55.0,68.5]$} \\
\hline & Employed & $28(13.3)$ & $0.0001+$ & {$[9.0,18.7]$} \\
\hline \multirow[t]{2}{*}{ Employment } & Unemployed & 182(86.7) & & {$[81.3,91.0]$} \\
\hline & $>10000 /$ month & $41(19.5)$ & $0.0001+$ & {$[14.4,25.5]$} \\
\hline \multirow[t]{4}{*}{ Monthly income } & $<10000 /$ month & 169(80.5) & & {$[74.5,85.6]$} \\
\hline & Muslim & $6(2.9)$ & - & {$[1.1,6.1]$} \\
\hline & Christian & $8(3.8)$ & & {$[1.7,7.4]$} \\
\hline & Buddhist & $32(15.2)$ & & {$[10.7,20.8]$} \\
\hline \multirow[t]{7}{*}{ Religion } & Hindu & $164(78.1)$ & & {$[71.9,83.5]$} \\
\hline & Magar, Pun & $11(5.2)$ & - & {$[2.6,9.2]$} \\
\hline & Others & $17(8.1)$ & & {$[4.8,12.6]$} \\
\hline & Newar & $17(8.1)$ & & {$[4.8,12.6]$} \\
\hline & Gurung & $21(10)$ & & {$[6.3,14.9]$} \\
\hline & Brahmin & 39(18.6) & & {$[13.6,24.5]$} \\
\hline & Chettri & $50(23.8)$ & & {$[18.2,30.2]$} \\
\hline \multirow[t]{7}{*}{ Ethinicity } & Dalit & $55(26.2)$ & & {$[20.4,32.7]$} \\
\hline & Labourer & $8(3.8)$ & - & {$[1.7,7.4]$} \\
\hline & Farmer & $8(3.8)$ & & {$[1.7,7.4]$} \\
\hline & Job holder & $12(5.7)$ & & {$[3.0,9.8]$} \\
\hline & Retired & $14(6.7)$ & & {$[3.7,10.9]$} \\
\hline & Others & 18(8.6) & & {$[5.2,13.2]$} \\
\hline & Housewife & $53(25.2)$ & & $\overline{[19.5,31.7]}$ \\
\hline Occupation & Student & $97(46.2)$ & & {$[39.3,53.2]$} \\
\hline
\end{tabular}

$+p<0.01$, statistically significant.

$-P$ value cannot calculate.

Schizophrenic patients received various types of treatment like ECT, drug and psychotherapy combined together. Most of the patients received a combination of drug therapy and psychotherapy. It was found that there was an association among different factors namely age, monthly income, religion and occupation and subsequent treatment given to the patients, which showed that $87.9 \%$ patients less than 40 years of age received a combination of psychotherapy and drug therapy whereas if the age of the patient was over 40 years they received drug therapy only. Religious background also indicates, there were $70.1 \%$ and $19.6 \%$ Hindus and Buddhists respectively. Likewise, $40 \%$ Dalit were followed by Chettri 24.3\% and Brahmin 19.6\%. 46.7\% were students followed by housewives $28 \%$ received a combination of both psychotherapy and drug therapy.

The most common antipsychotic drug prescribed was olanzapine. There was an association between the age of the patient and antipsychotics prescribed $(\mathrm{p}=0.001)$. It was revealed if the age is $<40$ years, Olanzapine was prescribed to $84.7 \%$ patients but if the age of the patient is > 40 yrs. Risperidone was commonly prescribed $45.9 \%$ $(\mathrm{p}=0.002)($ Table 4$)$.

\section{Commonest antipsychotics prescribed}

Olanzapine (Atypical Antipsychotics) was the commonest antipsychotic drug prescribed $34.3 \%$ followed by Haloperidol (Typical Antipsychotics) 28.6\%, combination of haloperidol and olanzapine 12.4\%, Risperidone 17.4\%, clozapine 3.8\%, Quetiapine 2.4\% and Aripiprazole 1\% (Atypical Antipsychotics) respectively.

\section{Determinants of antipsychotics use by logistic regression}

From the point of view of logistic regression analysis, it was found that Psychiatrist has a [OR 7.9, 95\% (CI 1.209, 51.84)] more tendency of prescribing medicines not from the essential drug list Nepal if the patient is from Gurung community as compared to Magar and Pun. Psychiatrist has 6.0 and 4.6 times more tendency of prescribing medicines not from the essential drug list of Nepal among students [OR 6.0(95\% $(1.332,27.324)]$ and housewives [OR 4.6(95\% $(0.979,22.010)]$ respectively. It is also observed that the tendency of using antipsychotic drugs by trade names were [OR $3.3(1.407,8.031]$ times more among male patients as compared to female ones. All the findings were statistically significant (Table 5).

\section{Discussion}

\section{Socio-demographic details and schizophrenia}

In the course of research, it was noticed that out of 210 cases of Schizophrenia, $58.76 \%$ of the cases involved males followed by $41.24 \%$ of females. The data shows that this finding resembles a research study conducted in Bangladesh as there also males suffer more with psychiatric disorder as compared to females [20]. However, this finding is different from a study done in Australia by Mant A et al. as it shows that Psychiatric illness is more common among female patients [21]. Most of the patients with Schizophrenia were below 40 years of age $78.6 \%$, whereas only $21.4 \%$ of the patients were over 40 years. Similar nature of finding was reported by Maki P et al. that schizophrenia is commonly prevalent among the adolescence [22]. Most of the patients of Schizophrenia were Hindus $78.1 \%$, followed by Buddhists $15.2 \%$, Christians 3.8\% and Muslims 2.9\% respectively. This could be due to the fact that Nepal is Hindu dominated country and obviously most of the patients are expected to be from Hindu religion. Ethnically, most of the patients were Dalit $26.2 \%$ followed by Chettri $23.8 \%$, Brahmin 18.6\%, Gurung 10\%, Newar 8.1\%, Magar and Pun $5.2 \%$ and others $8.1 \%$. The finding of present study is parallel to a study carried out by Kohrt BA in Nepal as the findings of the research stated that Psychiatric disorder is more common among Dalit/Nepali [23]. 
Table 2 Cross tabulation between socio demographic factors, national drug list of Nepal, generic and trade names

\begin{tabular}{|c|c|c|c|c|c|}
\hline \multicolumn{2}{|c|}{ Socio demographic factors } & \multicolumn{2}{|c|}{$\underline{\text { National drug list of Nepal }}$} & \multicolumn{2}{|c|}{ Generic/trade } \\
\hline Age & $>40 \mathrm{yrs}$ & $\begin{array}{l}\text { Essential drugs } \\
14(23.3)\end{array}$ & $\begin{array}{l}\text { Nonessential drugs } \\
31(20.7)\end{array}$ & $\begin{array}{l}\text { Generic } \\
5(20) \\
\end{array}$ & $\begin{array}{l}\text { Trade } \\
40(21.6)\end{array}$ \\
\hline & $<40$ yrs & $46(76.7)$ & 119(79.3) & $20(80)$ & $145(78.4)$ \\
\hline & P Value & & $0.400 x$ & & $0.545 x$ \\
\hline \multirow[t]{3}{*}{ Gender } & Female & $21(35)$ & 59(39.3) & $16(64)$ & $64(34.6))$ \\
\hline & Male & $39(65)$ & $91(60.7)$ & $9(36)$ & $121(65.4)$ \\
\hline & P Value & & $0.336 x$ & & $0.005+$ \\
\hline \multirow[t]{3}{*}{ Employment } & Employed & $10(16.7)$ & $18(12)$ & $3(12)$ & $25(13.5)$ \\
\hline & Unemployed & $50(83.3)$ & $132(88)$ & $22(88)$ & $160(86.5)$ \\
\hline & $P$ Value & & $0.246 x$ & & $0.565 x$ \\
\hline \multirow[t]{3}{*}{ Monthly income } & $>10000 /$ month & $13(21.7)$ & $28(18.7)$ & $7(28)$ & $34(18.4)$ \\
\hline & $<10000 /$ month & $47(78.3)$ & $122(81.3)$ & 18(88) & 151(81.6) \\
\hline & P Value & & $0.375 x$ & & $0.565 x$ \\
\hline \multirow[t]{5}{*}{ Religion } & Muslim & $0(0)$ & $6(4)$ & $0(0)$ & $6(3.2)$ \\
\hline & Christian & $0(0)$ & $8(5.3)$ & $0(0)$ & $8(4.3)$ \\
\hline & Buddhist & $7(11.3)$ & 25(16.7) & 2(8) & $30(16.2)$ \\
\hline & Hindu & $53(88.3)$ & $111(74)$ & $23(92)$ & $141(76.2$ \\
\hline & $P$ Value & & $0.059 x$ & & $0.312 x$ \\
\hline \multirow[t]{8}{*}{ Ethnicity } & Magar, Pun & $5(8.3)$ & $6(4)$ & $2(8)$ & $9(4.9)$ \\
\hline & Others & $0(0)$ & $17(11.3)$ & $0(0)$ & $17(9.2)$ \\
\hline & Newar & $3(5)$ & $14(9.3)$ & $3(12)$ & $14(7.6)$ \\
\hline & Gurung & 2(3.3) & 19(12.7) & $0(0)$ & $21(11.4)$ \\
\hline & Brahmin & $21(35)$ & $18(12)$ & $4(16)$ & $35(18.9)$ \\
\hline & Chettri & $13(21.7)$ & $37(24.7)$ & $10(40)$ & $40(21.6)$ \\
\hline & Dalit & $16(26.7)$ & $39(26)$ & $6(24)$ & $49(26.5)$ \\
\hline & $P$ Value & & $0.0001 \dagger$ & & $0.154 \times$ \\
\hline \multirow[t]{8}{*}{ Occupation } & Labour & $5(8.3)$ & $3(2)$ & $0(0)$ & $8(4.3)$ \\
\hline & Farmer & $2(3.3)$ & $6(4)$ & $0(0)$ & $8(4.3)$ \\
\hline & Jobholder & $3(5)$ & $9(6)$ & $3(12)$ & $9(4.9)$ \\
\hline & Retired & $7(11.7)$ & $7(4.7)$ & $0(0)$ & $14(7.6)$ \\
\hline & Others & $8(13.3)$ & $10(6.7)$ & $2(8)$ & $16(8.6)$ \\
\hline & Housewife & $14(23.3)$ & $39(26)$ & $10(40)$ & $43(23.2)$ \\
\hline & Student & $21(35)$ & $76(50.7)$ & $10(40)$ & $87(47)$ \\
\hline & P Value & & $0.053 x$ & & $0.190 x$ \\
\hline
\end{tabular}

$+p<0.01$, statistically significant.

$\times p>0.05$, statistically not significant.

Schizophrenia was commonly seen in individuals having monthly income less than 10000 NPR /month (80.5\%) and unemployed patients $(86.7 \%)$. This finding is analogous to the outcome of study done in Sweden by Lessen $\mathrm{E}$ et al. as the data showed that utilization of psychotropic drugs were more among individuals with low income [24]. Similarly, different researched findings confirmed that schizophrenia appears to have socioeconomic and racial dimensions. It is most commonly seen amongst the poor in the United States, England, Japan, Norway, Ireland and Iceland, but in the context of India and possibly in Italy it is more frequently witnessed among the rich. The disease is also common among urban dwellers and blacks in the United States [25]. As far as occupation of the patients is concerned, Schizophrenia was most commonly seen among students $46.2 \%$ followed by housewives $25.2 \%$, others $8.6 \%$ followed by retired persons $6.7 \%$, jobholders $5.7 \%$, farmers and labours $3.8 \%$. This is similar to the conclusion of research done by Banerjee et al. as it revealed that psychiatric disorders in Nepal found among housewives and students [26,27]. In a study from Bangladesh also reported that psychiatric disorder is common among students and housewives [20]. 
Table 3 Cross tabulation between socio demographic factors, groups of anti-psychotics, treatment given to the schizophrenic inpatient at the psychiatric ward

\begin{tabular}{|c|c|c|c|c|c|c|c|c|}
\hline \multicolumn{2}{|c|}{ Sociodemographic factors } & \multicolumn{3}{|c|}{ Groups of drugs } & \multicolumn{4}{|c|}{ Treatment } \\
\hline & & Miscellaneous & $\begin{array}{l}\text { Typical } \\
\text { antipsychotics }\end{array}$ & $\begin{array}{l}\text { Atypical } \\
\text { antipsychotics }\end{array}$ & ECT & $\begin{array}{l}\text { Drugs and } \\
\text { psychotherapy }\end{array}$ & Drug therapy & $\begin{array}{l}\text { Combined } \\
\text { therapy }\end{array}$ \\
\hline \multirow[t]{3}{*}{ Age } & $>40 \mathrm{yrs}$ & $3(11.5)$ & 14(23.3) & 28(22.6) & $2(100)$ & 13(12.2) & $27(36)$ & $3(11.5)$ \\
\hline & $<40 \mathrm{yrs}$ & $23(88.5)$ & $46(76.7)$ & 96(77.4) & $0(0)$ & 94(87.9) & $48(64)$ & $23(88.5)$ \\
\hline & $P$ value & $0.419 x$ & & & $0.0001+$ & & & \\
\hline \multirow[t]{3}{*}{ Gender } & Female & $21(80.8)$ & $39(65)$ & $70(56.5)$ & $2(100)$ & $44(41.1)$ & 29(38.7) & $5(15.4)$ \\
\hline & Male & $5(19.2)$ & $21(35)$ & $54(43.5)$ & $0(0)$ & 63(58.9) & $46(1.3)$ & $21(80.8)$ \\
\hline & $P$ value & $0.057 x$ & & & $0.05 \times$ & & & \\
\hline \multirow[t]{3}{*}{ Employment } & Employed & $2(7.7)$ & 10(16.7) & 16(12.9) & $0(0)$ & 18(16.8) & $8(10.7)$ & $2(7.7)$ \\
\hline & Unemployed & $24(92.3)$ & $50(83.3)$ & 108(87.1) & $2(100)$ & 89(83.2) & $67(89.3)$ & $24(92.3)$ \\
\hline & $P$ value & $0.519 x$ & & & $0.455 x$ & & & \\
\hline \multirow[t]{3}{*}{ Monthly income } & $>10000 /$ month & $4(15.4)$ & 13(21.7) & 24(19.4) & $2(100)$ & $26(24.3)$ & $9(12)$ & $4(15.4)$ \\
\hline & $<10000 /$ month & 22(84.6) & 47(78.3) & 100(80.6) & $0(0)$ & $81(75.7)$ & $66(88)$ & 22(84.6) \\
\hline & $P$ value & $0.794 x$ & & & $0.005+$ & & & \\
\hline \multirow[t]{5}{*}{ Religion } & Muslim & $0(0)$ & $0(0)$ & $6(4.8)$ & $0(0)$ & $3(2.8)$ & $3(4)$ & $0(0)$ \\
\hline & Christian & $0(0)$ & $0(0)$ & $8(6.5)$ & $0(0)$ & $8(7.5)$ & $0(0)$ & $0(0)$ \\
\hline & Buddist & $0(0)$ & $7(11.7)$ & $25(20.2)$ & $2(100)$ & 21(19.6) & $9(12)$ & $0(0)$ \\
\hline & Hindu & $26(100)$ & $53(88.3)$ & $85(65.5)$ & $0(0)$ & $75(70.1)$ & $63(84)$ & $26(100)$ \\
\hline & $P$ value & $0.003+$ & & & $0.0001+$ & & & \\
\hline \multirow[t]{8}{*}{ Ethinicity } & Magar, Pun & $0(0)$ & $5(8.3)$ & $6(4.8)$ & $2(100)$ & $5(4.7)$ & $4(5.3)$ & $0(0)$ \\
\hline & Others & $3(11.5)$ & $0(0)$ & 14(11.3) & $0(0)$ & $9(8.4)$ & $5(6.7)$ & $3(11.5)$ \\
\hline & Newar & $2(7.7)$ & $3(5)$ & $12(9.7)$ & $0(0)$ & $8(7.5)$ & $7(9.3)$ & $2(7.7)$ \\
\hline & Gurung & $0(0)$ & 2(3.3) & 19(15.3) & $0(0)$ & $16(15)$ & $5(6.7)$ & $0(0)$ \\
\hline & Brahmin & $6(23.1)$ & $21(35)$ & $12(9.7)$ & $0(0)$ & 21(19.6) & $12(16)$ & $6(23.1)$ \\
\hline & Chettri & $4(15.4)$ & 13(21.7) & $33(26.6)$ & $0(0)$ & $26(24.3)$ & $20(26.7)$ & $4(15.4)$ \\
\hline & Dalit & $11(42.3)$ & 16(28.6) & 28(22.6) & $0(0)$ & $22(40)$ & $22(40)$ & $11(20)$ \\
\hline & $P$ value & $0.0001+$ & & & $0.0001+$ & & & \\
\hline \multirow[t]{8}{*}{ Occupation } & Labour & $0(0)$ & $5(8.3)$ & $3(2.4)$ & $0(0)$ & $8(7.5)$ & $0(0)$ & $0(0)$ \\
\hline & Farmer & $2(7.7)$ & 2(3.3) & $4(3.2)$ & $0(0)$ & 4(3.7) & $2(2.7)$ & $2(7.7)$ \\
\hline & Job holder & $0(0)$ & $3(5)$ & $9(7.3)$ & $0(0)$ & $6(5.6)$ & $6(8)$ & $0(0)$ \\
\hline & Retired & $3(11.5)$ & $7(11.7)$ & $4(3.2)$ & $0(0)$ & $7(6.5)$ & $4(5.3)$ & $3(11.5)$ \\
\hline & Others & $2(7.7)$ & $8(13.3)$ & $8(6.5)$ & $2(100)$ & $2(1.9)$ & 14(18.7) & $2(7.7)$ \\
\hline & Housewife & $3(11.5)$ & 14(23.3) & $36(29)$ & $0(0)$ & $30(28)$ & $18(24)$ & $3(11.5)$ \\
\hline & Students & $16(61.5)$ & $21(35)$ & $60(48.4)$ & $0(0)$ & $50(46.7)$ & $31(41.3)$ & $16(61.5)$ \\
\hline & $\mathrm{P}$ value & 0.044 * & & & $0.0006+$ & & & \\
\hline
\end{tabular}

$\mathrm{tp}<0.01$, statistically significant.

${ }^{*} \mathrm{p}<0.05$, statistically significant.

$\times p>0.05$, statistically not significant.

\section{Drug utilization of antipsychotics \\ Drug therapy}

In most of the cases of Schizophrenia, drug therapy and psychotherapy treatments were used together 51\%; whereas in $35.7 \%$ cases were given either typical or atypical antipsychotics alone; in $12.4 \%$ cases a combination of multidrug were given comprising both typical and atypical antipsychotics and ECT was used only in 1\% of the cases of schizophrenia. Psychotherapy was not used alone in none of the cases. It showed that psychotherapy along with drug therapy is more commonly used in schizophrenia management.

Most of the drugs were prescribed by trade names $88.1 \%$ whereas only $11.9 \%$ of the drugs were prescribed by generic name. This is similar to a study done in 2001 by PR Ravishankar on psychotropic drug utilization which also shows that $71.3 \%$ of the drugs were prescribed by trade names in Nepal [15]. In a different study done in the tertiary care hospital in Nepal indicates the low use of drugs by generic names in the past 
Table 4 Coss tabulation between socio demographic factors and neuroleptics prescribed

\begin{tabular}{|c|c|c|c|c|c|c|c|c|c|}
\hline \multicolumn{2}{|c|}{ Socio demographic factors } & \multicolumn{8}{|c|}{ Antipsychotics prescribed } \\
\hline & & \multirow{2}{*}{$\begin{array}{l}\text { Aripriprazole } \\
\text { N05AX12 }\end{array}$} & \multirow{2}{*}{$\begin{array}{l}\text { Quetiapine } \\
\text { N05AH04 }\end{array}$} & \multirow{2}{*}{$\begin{array}{l}\text { Clozapine } \\
\text { N05AH02 }\end{array}$} & \multirow{2}{*}{$\begin{array}{l}\text { Risperidone } \\
\text { N05AX08 }\end{array}$} & \multirow{2}{*}{$\begin{array}{l}\text { Haloperidol } \\
\text { \& Olanzapine }\end{array}$} & \multirow{2}{*}{$\begin{array}{l}\text { Haloperidol } \\
\text { N05AD01 }\end{array}$} & \multirow{2}{*}{$\begin{array}{l}\text { Olanzapine } \\
\text { N05AH03 } \\
\end{array}$} & \multirow[t]{2}{*}{ P Value } \\
\hline & & & & & & & & & \\
\hline & $>40 \mathrm{yrs}$ & $0(0)$ & $0(0)$ & $0(0)$ & $17(45.9)$ & $3(11.5)$ & $14(23.3)$ & $11(15.3)$ & $0.002+$ \\
\hline \multirow[t]{2}{*}{ Age } & $<40$ yrs & $2(100)$ & $5(100)$ & $8(100$ & $20(54.1)$ & $23(88.5)$ & $46(76.7)$ & $61(84.7)$ & \\
\hline & Female & $0(0)$ & $3(60)$ & $3(37.5)$ & 19(51.4) & $5(19.2)$ & $21(35)$ & $29(40.3)$ & $0.156 x$ \\
\hline \multirow[t]{2}{*}{ Gender } & Male & $2(100)$ & $2(40)$ & $5(62.5)$ & 18(48.6) & $21(80.8)$ & $39(65)$ & $43(59.7)$ & \\
\hline & Employed & $0(0)$ & $0(0)$ & $2(25)$ & $0(0)$ & $2(7.7)$ & $10(16.7)$ & 14(19.4) & $0.079 x$ \\
\hline \multirow[t]{2}{*}{ Employment } & Unemployed & $2(100)$ & $5(100)$ & $6(75)$ & $37(100)$ & 24(92.3) & $50(83.3)$ & $58(80.6)$ & \\
\hline & $>10000 /$ month & $0(0)$ & $0(0)$ & $0(0)$ & $9(24.3)$ & $4(15.4)$ & $13(21.7)$ & $15(20.8)$ & $0.580 x$ \\
\hline \multirow[t]{4}{*}{ Monthly income } & $<10000 /$ month & $2(100)$ & $5(100)$ & $8(100)$ & $28(75.7)$ & $22(84.6)$ & $47(78.3)$ & $57(79.2)$ & \\
\hline & Muslim & $0(0)$ & $0(0)$ & $0(0)$ & $0(0)$ & $0(0)$ & $0(0)$ & $6(8.3)$ & $0.001 \dagger$ \\
\hline & Christian & $0(0)$ & $0(0)$ & $0(0)$ & $3(8.1)$ & $0(0)$ & $0(0)$ & $5(6.9)$ & \\
\hline & Buddhist & $0(0)$ & $2(40)$ & $8(100)$ & $10(27)$ & $0(0)$ & $7(11.7)$ & $13(18.1)$ & \\
\hline \multirow[t]{7}{*}{ Religion } & Hindu & $2(100)$ & $3(60)$ & $0(0)$ & $24(64.9)$ & $26(100)$ & 53(88.3) & $48(66.7)$ & \\
\hline & Magar, Pun & $0(0)$ & $2(40)$ & $0(0)$ & $0(0)$ & $0(0)$ & $5(8.3)$ & $4(5.6)$ & $0.001+$ \\
\hline & Others & $0(0)$ & $0(0)$ & $0(0)$ & $3(8.1)$ & $3(11.5)$ & $0(0)$ & $11(15.3)$ & \\
\hline & Newar & $0(0)$ & $0(0)$ & $0(0)$ & $7(18.9)$ & $2(7.7)$ & $3(5)$ & $5(6.9)$ & \\
\hline & Gurung & $0(0)$ & $0(0)$ & $0(0)$ & $10(27)$ & $0(0)$ & 2(3.3) & $9(12.5)$ & \\
\hline & Brahmin & $0(0)$ & $0(0)$ & $0(0)$ & $2(5.4)$ & $6(23.1)$ & $21(35)$ & 10(13.9) & \\
\hline & Chettri & $2(100)$ & $3(60)$ & $0(0)$ & $6(16.2)$ & $4(15.4)$ & $13(21.7)$ & $22(30.6)$ & \\
\hline \multirow[t]{7}{*}{ Ethinicity } & Dalit & $0(0)$ & $0(0)$ & $8(100)$ & $9(24.3)$ & $11(42.3)$ & $16(26.7)$ & $11(15.3)$ & \\
\hline & Labourer & $0(0)$ & $0(0)$ & $0(0)$ & $0(0)$ & $0(0)$ & $5(8.3)$ & $3(4.2)$ & $0.12 x$ \\
\hline & Farmer & $0(0)$ & $0(0)$ & $2(25)$ & $0(0)$ & $2(7,7)$ & $2(3.3)$ & $2(2.8)$ & \\
\hline & Job holder & $0(0)$ & $0(0)$ & $0(0)$ & $0(0)$ & $0(0)$ & $3(5)$ & $9(12.5)$ & \\
\hline & Retired & $0(0)$ & $0(0)$ & $0(0)$ & $2(5.4)$ & $3(11.5)$ & $7(11.7)$ & $2(2.8)$ & \\
\hline & Others & $0(0)$ & $0(0)$ & $0(0)$ & $4(10.8)$ & $2(7.7)$ & 813.3) & $4(5.6)$ & \\
\hline & Housewife & $0(0)$ & $0(0)$ & $0(0)$ & 11(29.7) & $3(11.5)$ & $14(23.3)$ & $25(34.7)$ & \\
\hline Occupation & Student & $2(100)$ & $5(100)$ & $6(75)$ & $20(54.1)$ & $16(61.5)$ & $21(28.6)$ & $27(37.5)$ & \\
\hline
\end{tabular}

$+p<0.01$, statistically significant.

$\times p>0.05$, statistically not significant.

[28-30]. In MTH, the patient has to pay for the medications. Published evidence also has revealed by promoting the use of drugs by trade name will increase the cost of the therapy where other generic alternatives are available [31].

Antipsychotic drugs that have been included in the essential drug list of Nepal are Chlorpromazine, Fluphenazine, Haloperidol and Thioridazine [32]. Essential drugs were used in $28.6 \%$ Schizophrenia cases, which is quite similar to another study done by P.R Ravishankar on utilization of psychotropic drugs concluding that only $29.48 \%$ drugs were used from essential drug list of Nepal [15]. In a study done by Upadhyay in Nepal also shows that the prescribing drugs from essential drug list were low $37.09 \%$ [29]. This is a matter of concern and need to deal with by prescriber education, training campaigns are required to improve the therapeutic management of the patient and ensure better quality of life [15,33].
This study can serve as an outline for drug prescribing pattern and further research is required in this direction to improve the practice of prescribing pattern. Several other studies also shows that drug utilization study may be helpful for therapeutic audit and hypothesis generation for the improvement of prescribing pattern of drugs [34].

\section{Typical and atypical antipsychotics}

As evident in the present study, most of the patients received atypical antipsychotics 59\%, typical antipsychotics were used only in $28.6 \%$ of cases and in remaining cases a combination of typical and typical antipsychotics were used $12.4 \%$. Olanzapine was the commonest antipsychotic drug being prescribed $34.3 \%$ followed by Haloperidol 28.6\%, combination of haloperidol and olanzapine $12.4 \%$, Risperidone $17.4 \%$, Clozapine $3.8 \%$, Quetiapine 2.4\% and Aripiprazole 1\%. The finding of this 
Table 5 Logistic regression table of non-essential drugs (drugs not included in the national list of essential drugs of Nepal), trade name and socio demographic factors

\begin{tabular}{|c|c|c|c|}
\hline \multicolumn{2}{|c|}{ Socio demographic factors } & \multirow{2}{*}{$\begin{array}{c}\text { Nonessential drugs } \\
\text { Odds ratio (confidence interval) } \\
1\end{array}$} & \multirow{2}{*}{$\begin{array}{c}\text { Trade } \\
\text { Odds ratio (confidence interval) } \\
1\end{array}$} \\
\hline & $>40 \mathrm{yrs}$ & & \\
\hline Age & $<40$ yrs & $1.168(0.570,2.393) \times$ & $0.906(0.320,2.566) \times$ \\
\hline & Female & 1 & 1 \\
\hline Gender & Male & $0.831(0.445,1.549) \times$ & $3.361(1.407,8.031) \dagger$ \\
\hline \multirow{3}{*}{ Employment } & Employed & 1 & 1 \\
\hline & Unemployed & $1.467(0.634,3.393) \times$ & $0.873(0.243,3.132) \times$ \\
\hline & $>10000 /$ month & 1 & 1 \\
\hline \multirow[t]{4}{*}{ Monthly income } & $<10000 /$ month & $1.205(0.576,2.523) \times$ & $1.727(0.669,4.461) \times$ \\
\hline & Muslim & 1 & 1 \\
\hline & Christian & 1 & - \\
\hline & Buddhist & - & - \\
\hline \multirow[t]{7}{*}{ Religion } & Hindu & - & - \\
\hline & Magar, Pun & 1 & 1 \\
\hline & Others & - & - \\
\hline & Newar & $3.889(0.695,21.749) \times$ & - \\
\hline & Gurung & $7.917(1.209,51.841)^{*}$ & - \\
\hline & Brahmin & $0.714(0.186,2.737) \times$ & - \\
\hline & Chettri & $2.372(0.618,9.099) \times$ & - \\
\hline \multirow[t]{7}{*}{ Ethnicity } & Dalit & $2.031(0.542,7.617) \times$ & - \\
\hline & Labour & 1 & 1 \\
\hline & Farmer & $5.0(0.584,42.797) \times$ & - \\
\hline & Jobholder & $5.0(0.720,34.726) \times$ & $1.037(0.144,7.477) \times$ \\
\hline & Retired & $1.667(0.283,9.822) \times$ & - \\
\hline & Others & $2.083(0.378,11.482) \times$ & $1.944(0.306,12.350) \times$ \\
\hline & Housewife & $4.643(0.979,22.010)^{*}$ & $0.889(0.165,4.777) \times$ \\
\hline Occupation & Student & $6.032(1.332,27.324)^{*}$ & $1.815(0.315,10.455) \times$ \\
\hline
\end{tabular}

$\mathrm{tp}<0.01$, statistically significant.

${ }^{*} p<0.05$, statistically significant.

$\times p>0.05$, statistically not significant.

- $P$ value cannot calculate.

study is similar to the conclusion of research conducted by Dutta et al. at Uttaranchal, India in the year 20022003. His finding revealed that among the used antipsychotics, Olanzapine was prescribed most commonly 44.4\% followed by Haloperidol 28.5\%, Risperidone 9.5\%, Quetiapine 6.3\%, Aripiprazole5.2\%, Ziprasidone, 4.2\%, and Thioridazine $2.6 \%$ [35].

In a study done by Piparva KG et al. in India shows that the use of atypical antipsychotic drugs are used higher $43.83 \%$ than typical antipsychotic drug $26.32 \%$ [36]. Similar nature of studies carried out across the world also indicated the recent trend of use of atypical antipsychotics [37].

The published evidence confirms that atypical antipsychotics might be suitable for schizophrenic patients and better tolerated as compared to the typical antipsychotic drugs. The treatment pattern observed correlates with the world wide changing trends in the treatment of Schizophrenia [33].

In recent years, the induction of newer atypical antipsychotic agents like Olanzapine, Risperidone, Quetiapine and Ziprasidone have provided a better control of symptoms and reduced the chances of adverse effects especially the extrapyramidal ones in contrast with typical antipsychotic drugs. The newer atypical antipsychotics also proved to be better in improving negative symptoms, cognitive dysfunction and also efficacious in antipsychotic resistant schizophrenia [36].

Typical antipsychotics act through Dopaminergic pathway in the mesolimbic and mesofrontal pathway and are associated with extrapyrimidal adverse effects by blocking the D2 receptors in the brain. It is not seen with the atypical antipsychotics as they act through serotenergic pathways of brain. Atypical antipsychotics 
can also treat the negative symptoms during this disorder whereas the typical antipsychotics can only treat the positive symptoms $[38,39]$. Systematic review has shown that Olanzapine is more efficacious than other second generation antipsychotic drugs [40].

\section{Limitation}

This research is based on the hospital study from Western Development Region of Nepal. A multi centric hospital based study with higher sample size will be beneficial to assess the current trend of antipsychotics all over Nepal.

\section{Conclusion}

According to the utilization pattern of antipsychotics, it is concluded that atypical antipsychotics were used relatively more commonly than that of typical antipsychotics. Among the atypical antipsychotic drugs, there is a trend of using Olanzapine during Schizophrenia as compared to other atypical antipsychotic drugs in Western Nepal.

\section{Abbreviations \\ NPR: Nepalese rupees Yrs: Years MTH: Manipal teaching hospital.}

\section{Competing interests}

The authors do not have any conflict of interest arising from the study.

\section{Authors' contribution}

IB designed the study, deduced the data, drafted the manuscript, and revised it. BR, PKC and IB2 planned the study with IB, acquired the data, conducted the data analysis, interpreted the data, and revised the manuscript. IB2 has also participated in the language editing along with IB and BR. BS participated in statistical analysis, interpreted the data, and revised the manuscript. PKS and ACS critically revised the manuscript. All the authors approved the final document.

\section{Authors' information}

Dr. Indrajit Banerjee MBBS, MD Pharmacology. Currently working as a Lecturer in the Department of Pharmacology, Manipal College of Medical Sciences, Pokhara, Nepal and Chief of Manipal Sanjeevani Clinic. He is the Chief Editor of International Journal of Physiology and Pharmacology (IJPP), Managing Editor of International Journal of Brain Research (IJBR), Section Editor of Nepal Journal of Epidemiology (NJE). He is an Organizing Committee member of International Epidemiological Association Conference 2013 and Confederation of Epidemiological Associations (CEA) Conference December 2013 Organized by Mahatma Gandhi University. He is also Assistant Secretary General of CEA. Mr. Bedanta Roy MSc Physiology. Currently working as Assistant Professor in the Department of Physiology, Manipal College of Medical Sciences, and Pokhara, Nepal. He is at present pursuing PhD in Neurophysiology. He is the Chief Editor of International Journal of Brain Research (IJBR), Managing editor of International Journal of Physiology and Pharmacology (IJPP), Section Editor of Nepal Journal of Epidemiology (NJE). He is an Organizing Committee member of International Epidemiological Association Conference 2013 and Confederation of Epidemiological Associations (CEA) Conference December 2013. He is also Assistant Secretary General of CEA.

Dr. Brijesh Sathian MD(AM), PhD. working as Assistant Professor and Biostatistics Chief in the Department of Community Medicine, Manipal College of Medical Sciences, Pokhara, Nepal. He is the editorial board member of NJE, IJBS, AlIJMS, GMJ, IJPP, IJBR and Joint Organizing Secretory and treasurer of International Epidemiological Association Conference 2013. Joint Organizing Secretary CEA (Confederation of Epidemiological Associations) Conference December 2013 Organized by Mahatma Gandhi University. He is also the President of CEA.

Dr. P.K. Chakraborty MBBS, MD Psychiatry. Currently working as Professor in the Department of Psychiatry and Hospital Director Manipal Teaching
Hospital, Pokhara, Nepal. He is an organizing committee member of International Epidemiological Association Conference 2013.

Dr. Archana Saha MBBS, MD Pharmacology. Currently working as Professor and Head in the Department of Pharmacology Manipal College of Medical Sciences, Pokhara, Nepal. She is the editorial board member of NJMS. She is organizing committee member of International Epidemiological Association Conference 2013.

Dr. Indraneel Banerjee, MBBS, MS, MRCS. Currently working as a Senior Resident, R. G. Kar Medical College, Kolkata, West Bengal, India.

\section{Acknowledgments}

We lengthen our heartfelt and cordial gratitude to Late Dr Akhilesh Chandra Jauhari, Professor, Department of Pharmacology, Manipal College of Medical sciences, Nepal for all guidance, proposition and cooperation in writing this paper. We are grateful to Dr. B. M. Nagpal, Dean and CEO, MCOMS, Nepal. We are also thankful to Dr Shishir Gokhale, Director of Basic Sciences and Head of the department of Microbiology for giving me constant support. We are grateful to Dr S. M.Banerjee, Orthopaedic surgeon, Kalyani, West Bengal, India and K Ramesh ,HOD, Psychiatry for constant help and support. Lastly we would like to thank, Mr. Shovit Khadka, Lecturer, English, Kalika Multiple Campus, Pokhara, Nepal (affiliated to Tribhuvan University) for grammar and language editing.

\section{Author details}

${ }^{1}$ Department of Pharmacology, Manipal College of Medical Sciences, Pokhara, Nepal. '2Department of Physiology, Manipal College of Medical Sciences, Pokhara, Nepal. ${ }^{3}$ Department of Community Medicine, Manipal College of Medical Sciences, Pokhara, Nepal. ${ }^{4}$ R. G. Kar Medical College, Kolkata, West Bengal, India. ${ }^{5}$ Manipal Teaching Hospital, Pokhara, Nepal. ${ }^{6}$ Department of Pharmacology, Manipal College of Medical Sciences, Pokhara, Nepal.

Received: 2 September 2012 Accepted: 18 March 2013

Published: 22 March 2013

\section{References}

1. Lee D, Bergmen U: Studies of utilization. In Pharmacoepidemiology. 1st edition. Edited by Strom BC. New York: Churchill Livingstone; 1989:259-73.

2. Uppal R: Drug utilization studies: a brief overview. Annual update in clinical Pharmacology. 1993, 1:54-55.

3. Saha S, Chant D, Welham J, McGrath J: A systematic review of the prevalence of schizophrenia. PLoS Med 2005, 2:e141.

4. Bhugra D: The global prevalence of schizophrenia. PLoS Med 2005 May, 2(5):e151.

5. Robin RW, Gottesman II, Albaugh B, Goldman D: Schizophrenia and psychotic symptoms in families of two American Indian tribes. $B M C$ Psychiatry 2007, 7:30.

6. MCGrath JJ, Susser ES: New directions in the epidemiology of schizophrenia. Med J Aust 2009 Feb 16, 190(4 Suppl):S7-9.

7. McGrath J, Saha S, Chant D, Welham J: Schizophrenia: a concise overview of incidence, prevalence, and mortality. Epidemiol Rev 2008, 30:67-76. doi:10.1093/epirev/mxn001. Epub 2008 May 14.

8. Jha A, Ranjan S, Pradhan PK, Jha T: Challenges of setting up psychiatric services in Nepal: Lessons from the first year of Janakpur Project. Asian J Psychiatr 2011, 4(4):297-9. doi:10.1016/j.ajp.2011.10.004. Epub 2011 Dec 6.

9. Shrestha MR, Sherchan S, Shakya R, Joshi D: Monthly pattern of psychiatric morbidity and duration of stay among the patients admitted in Mental Hospital, a central level tertiary care hospital. Nepal Med Coll J 2011 Jun, 13(2):133-6.

10. Tausig M, Subedi S, Subedi J, Ross J, Broughton LC, Singh R, Blangero J, WilliamsBlangero S: Mental illness in Jiri Nepal. The Jirel issue 2000, 27:105-15. Jan.

11. Jablensky A, Sartorius N, Ernberg G, Anker M, Korten A, Cooper JE, Day R, Bertelsen A: Schizophrenia: manifestations, incidence and course in different cultures. A World Health Organization ten-country study. Psychol Med Monogr Suppl 1992, 20:1-97.

12. Hartling L, Abou-Setta AM, Dursun S, Mousavi SS, Pasichnyk D, Newton AS: Antipsychotics in adults with schizophrenia: comparative effectiveness of first-generation versus second-generation medications: a systematic review and meta-analysis. Ann Intern Med 2012 Oct 2, 157(7):498-511.

13. Tamrakar SM, Nepal MK, Koirala NR, Sharma VD, Gurung CK, Adhikari SR: An open, randomized, comparative study of efficacy and safety of 
risperidone and haloperidol in schizophrenia. Kathmandu Univ Med J (KUMJ) 2006, 4(2):152-60

14. Shankar PR, Partha P, Shenoy N: Self-medication and non-doctor prescription practices in Pokhara valley. Western Nepal: a questionnairebased study. BMC Fam Pract. 2002 Sep 17, 3:17

15. Shankar PR, Roy S: Patterns of prescription and drug use in psychiatry outpatient department in a teaching hospital in Western Nepal. The Internet Journal of Pharmacology 2002, 1(2). Available from: http://archive.ispub.com/ journal/the-internet-journal-of-pharmacology/volume-1-number-2/patternsof-prescription-and-drug-use-in-a-psychiatry-out-patient-department-in-ateaching-hospital-in-western-nepal.html\#sthash.7PDv6HuB.dpbs.

16. Nervous System. ATC/DDD Index: WHO collaborating centre for drug statistics methodology. [online] 2011 [cited 2013 Mar 4]. 2013. Available from: URL: http://www.whocc.no/atc_ddd_index/

17. World Health Organization: The ICD-10 Classification of mental and behavioral disorders (Tenth Revision). Geneva: Diagnostic criteria for research; 1992.

18. Sathian B, Sreedharan J, Baboo NS, Sharan K, Abhilash ES, Rajesh E: Relevance of Sample Size Determination in Medical Research. Nepal Journal of Epidemiology 2010, 1(1):4-10.

19. Sathian B: Reporting dichotomous data using Logistic Regression in Medical Research: The scenario in developing countries. Nepal Journal of Epidemiology 2011, 1(4):111-113.

20. Fahmida A, Wahab MA, Rahman MM: Pattern of psychiatric morbidity among the patients admitted in a private psychiatric clinic. Bangladesh Journal of Medical Science 2009, 8(1-2):23-28.

21. Mant A, Lansbury G, Bridges-Webb C: Trends in psychotropic drug prescribing in Australia. Med J Aust 1987, 146(4):208-10.

22. Maki P, Veijola J, Jones PB, Murray GK, Koponen H, Tienari P, Miettunen J, Tanskanen P, Wahlberg KE, Koskinen J, Lauronen E, Isohanni M: Predictors of schizophrenia-a review. Br Med Bull 2005 Jun 9, 73-74:1-15.

23. Kohrt BA, Speckman RA, Kunz RD, Baldwin JL, Upadhaya N, Acharya NR, Sharma VD, Nepal MK, Worthman CM: Culture in psychiatric epidemiology: Using ethnography and multiple mediator model to assess the relationship of caste with depression and anxiety in Nepal. Ann Hum Biol 2009, 36:261-80

24. Lesen E, Anderrson K, Petzoid M, Carlsten A: Socioeconomic determinants of Psychotropic drug utilization among elderly: a national population based cross sectional study. BMC Publ Health 2010, 10:118.

25. Foster HD: The Geography of Schizophrenia: Possible Links with Selenium and Calcium Deficiencies, Inadequate Exposure to Sunlight and Industrialization. Journal of Orthomolecular Medicine 1988, 3(3):135-40.

26. Banerjee I, Roy B, Sathian B, Banerjee I, Kumar SS, Saha A: Medications for Anxiety: A Drug utilization study in Psychiatry Inpatients from a Tertiary Care Centre of Western Nepal. Nepal Journal of Epidemiology 2010, 1(4):119-25.

27. Banerjee I, Roy B, Banerjee I, Sathian B, Mondol M, Saha A: Depression and its Cure: A Drug Utilization Study from a Tertiary Care Centre of Western Nepal. Nepal Journal of Epidemiology 2011, 1(5):144-52.

28. Alam K, Mishra P, Prabhu M, Shankar PR, Palaian S, Bhandari RB, Bista D: A study on rational drug prescribing and dispensing in outpatients in a tertiary care teaching hospital of Western Nepal. Kathmandu Univ Med J (KUMJ) 2006, 4(4):436-43.

29. Upadhyay KD, Palaian S, Shankar PR, Mishra P: Rational drug prescribing and dispensing in a tertiary care teaching hospital of Western Nepal. Journal of Institute of Medicine 2008 Aug, 30(2):33-38.

30. Shankar PR, Partha P, Nagesh S: Prescribing pattern in medical outpatients. Int J Clin Pract 2002, 56:549-51.

31. Steinman MA, Chren MM, Landefeld CS: What's in a name? Use of brand versus generic drug names in United States outpatient practice. J Gen Intern Med 2007 May, 22(5):645-8.

32. Kafle KK, Prasad RR, Thapa BB: National List of Essential Medicine (forth revision draft). 2nd edition. Kathmandu: Nepalese National Formulary; 2010:443.

33. Bret $P$, Bret MC, Queuille E: Prescribing patterns of antipsychotics in 13 French psychiatric hospitals. Encephale 2009, 35(2):129-38. doi:10.1016/j. encep.2008.03.007. Epub 2008 Jul 7.

34. Hurley SF, McNeil JJ, Jolley DJ, Harvey R: Linking prescription and patientidentifying data: a pilot study. Med J Aust 1992 Mar 16, 156(6):383-6.

35. Dutta SB, Dhasmana DC, Bhardwaj R: Psychotropic drug utilization pattern among patients with schizophrenia. Indian J Psychiatry 2005 Oct, 47(4):243-4.
36. Piparva KG, Parmar DM, Singh AP, Gajera MV, Trivedi HR: Drug utilization study of psychotropic drugs in outdoor patients in a teaching hospital. Indian J Psychol Med 2011 Jan, 33(1):54-8.

37. Bret MC, Bret $P$, Pariente A, Fourier-Réglat $A$ : The use of atypical antipsychotics in French psychiatric hospitals. Pharm World Sci 2007 29(5):551-6. Epub 2007 Jul 19.

38. Kafle KK, Prasad RR, Thapa BB: National List of Essential Medicine (forth revision draft). 2nd edition. Kathmandu: Nepalese National Formulary; 2010:140-144.

39. Serretti A, De Ronchi D, Lorenzi C, Berardi D: New antipsychotics and schizophrenia: a review on efficacy and side effects. Curr Med Chem 2004 Feb, 11(3):343-58.

40. Komossa K, Rummel-Kluge C, Hunger H, Schmid F, Schwarz S, Duggan L, Kissling W, Leucht S: Olanzapine versus other atypical antipsychotics for schizophrenia. Cochrane Database Syst Rev 2010 Mar 17, 3, CD006654.

\section{doi:10.1186/1471-244X-13-96}

Cite this article as: Banerjee et al:: Socio demographic profile and utilization pattern of antipsychotic drugs among schizophrenic inpatients: a cross sectional study from western region of Nepal. BMC Psychiatry 2013 13:96.

\section{Submit your next manuscript to BioMed Central and take full advantage of:}

- Convenient online submission

- Thorough peer review

- No space constraints or color figure charges

- Immediate publication on acceptance

- Inclusion in PubMed, CAS, Scopus and Google Scholar

- Research which is freely available for redistribution 